\title{
THE SCIENTIFIC WORK OF C. L. E. MOORE
}

In the death of Clarence Lemuel Elisha Moore the Massachusetts Institute of Technology loses an outstanding educator, and the United States one of its most prominent geometers. Born in Bainbridge, Ohio, May 12, 1876, from settler stock, he decided upon a career of study, and received the degree of B.Sc. from the Ohio State University in 1901, the degree of A. M. from Cornell in 1902, and the degree of Ph.D. from Cornell in 1904. He also studied at the universities of Göttingen, Turin, and Bonn, where he came under the influence of Segre and Study. In 1904 he joined the staff of the Massachusetts Institute of Technology, where he taught successively as instructor, assistant professor, associate professor, and full professor. He died December 5, 1931, after a surgical operation. He is survived by his wife, Belle Pease Fuller, and a daughter, Hazel.

As a member of the teaching staff at the Massachusetts Institute of Technology he was responsible for a great deal of the increased mathematical activity at this institute in the last twenty years, not only through his own research but also in his constant encouragement of the work of others. Students and members of the staff liked to talk things over with Moore, and many a scientific or educational opinion has ripened in the discussion with him.

His mathematical work shows a remarkable unity, combined with intuition for living problems and elegance of geometric conception. Starting from problems on algebraic geometry in ordinary space, following Klein, Segre, and Study, he soon became interested in spaces of more dimensions, then in the differential geometry of such spaces, and at last in the differential geometry of Riemannian manifolds. He belongs, with Ricci, for whom he had a great admiration, to the group of geometers who had the satisfaction of seeing the usefulness of their efforts recognized by later developments. With Ricci and Study he also shared the Leibnizian conviction of the importance of the formal side of the computation, and to this we owe work (in collaboration with $\mathrm{H}$. B. Phillips) in vector analysis and related subjects.

Some of his major contributions to geometry are the investigation of minimal planes, his theory (together with Phillips) of linear distance and angle in projective geometry, his theory (together with E. B. Wilson) of two-dimensional surfaces in hyperspace, his study of remarkable surfaces in hyperspace (rotation surfaces, minimal surfaces, developable surfaces) and of interesting curves on manifolds lying in hyperspace. A series of investigations (together with Philip Franklin) on the geometric properties of Pfaffians occupied his mind at the time he was stricken.*

Though deeply interested in those modern investigations which tend to broaden the concept of differential geometry by the study of different dis-

* A detailed analysis of Moore's personality and scientific work will appear in the Journal of Mathematics and Physics, of which he was one of the founders. 
placements, Moore devoted most of his research to the study of the many unknown properties of euclidean and riemannian hyperspace. The deep scientific wisdom of this decision becomes clear only to him who realizes how little we know of the detailed aspects of such manifolds, how surprising the results may be, and how important a thorough investigation is, not only for differential geometry, but also for topology, calculus of variations, and even physics. In this field Moore stands as sturdy a pioneer as his ancestors were in the woods of the Middle West.

D. J. STRUIK 